\title{
A simulation of traffic noise emissions at a roundabout based on a cellular automaton model
}

\author{
Canyi $\mathrm{Du}^{1}$, Xinfa $\mathrm{Qiu}^{1}, \mathrm{Feng} \mathrm{Li}^{1,{ }^{*}}$ (D), and Ming $\mathrm{Cai}^{2}$ \\ ${ }^{1}$ School of Automotive and Transportation Engineering, GuangDong Polytechnic Normal University, 510665 Guangzhou, PR China \\ ${ }^{2}$ Research Center of Intelligent Transport Systems, School of Intelligent Systems Engineering, Sun Yat-sen University, \\ 510006 Guangzhou, PR China
}

Received 18 May 2021, Accepted 17 September 2021

\begin{abstract}
The calculation and evaluation of traffic noise is an important task in urban road design. Roundabouts are a common form of urban road intersection. The complexity of traffic operations makes the calculation of traffic noise near a roundabout challenging. To explore traffic noise at roundabouts, a cellular automaton traffic flow model for a two-lane roundabout is established. Based on this model, a dynamic simulation method for traffic noise at roundabouts is proposed. The traffic operation and noise emissions at a roundabout are simulated. The vehicle speed distribution and traffic noise distribution at the roundabout are analysed, and the relationship between the traffic volume and sound power level of the cells is discussed. Finally, the proposed method is compared with existing traffic noise models, and the accuracy and efficiency of the proposed method are verified. The results of this paper show that the speed distribution and noise emission distribution at the roundabout are not uniform. When the traffic volume increases to saturation, the noise emission on the ring road will not keep increasing, and the sound power level of the cells on the inner ring is approximately $2 \mathrm{dBA}$ higher than that of the outer ring. The methods and results in this paper may be valuable for road traffic design and noise control.
\end{abstract}

Keywords: Roundabout, Cellular automaton model, Traffic noise, Dynamic simulation

\section{Introduction}

With continued urbanization, noise pollution has become a worldwide problem threatening public health [1]. Many studies have shown that long-term exposure to high-intensity noise may cause annoyance [2], sleep disorders [3], learning impairments [4, 5], and even heart disease [6]. The equivalent sound level $\left(L_{\mathrm{eq}}\right)$ calculated by the energy average principle is currently used as the main traffic noise evaluation index. However, significant variance in community response to road traffic noise was reported in a recent meta-analysis performed by the World Health Organization, which was attributed to the use of an energy-average noise indicator as the sole predictor of adverse effects $[7,8]$. To complement the use of standard energy-average noise levels, other more effective traffic noise assessment methods have been proposed, including statistical analysis [9] and several supplementary noise indicators that describe the emergence of identifiable noise events [10-12]. The equivalent sound level $\left(L_{\mathrm{eq}}\right)$ can generally be predicted by conventional traffic noise prediction models with reasonable accuracy, but these models are unable to

*Corresponding author: lifeng@gpnu.edu.cn assess the temporal dynamics of noise. To predict the temporal dynamics and statistical sound levels of noise, dynamic traffic noise modelling is required.

At present, the main traffic noise prediction models can be divided into static models and dynamic models. Some classic road traffic noise prediction models, such as the FHWA model in the United States [13, 14], the CNOSSOS model in Europe [15], the CORTN model in the United Kingdom [16], and the ASJ-RTN model in Japan [17], are all static models. Static models generally use the average speed of the road to calculate the noise emission of the vehicle, making them suitable for predicting the equivalent sound level $L_{\mathrm{eq}}$ over a period of time; however, they cannot predict the temporal dynamics of noise. To improve the prediction accuracy at an intersection, some static models also provide acceleration correction or intersection correction $[18,19]$. Different from static models, dynamic traffic noise models simulate the running process of traffic flows, collect the real-time motion parameters of each vehicle, such as speed and acceleration, and use these parameters to calculate the real-time noise emissions from each vehicle. Then, the instantaneous noise energy contribution of each vehicle is superimposed to obtain an instantaneous sound level at the receiving point. A dynamic traffic noise model 
can obtain an instantaneous sound level that dynamically changes over a period of time. Using the statistics of the instantaneous sound level, more noise evaluation indicators can be predicted, such as the statistical sound level, equivalent sound level, traffic noise index, etc. To obtain the realtime motion state parameters of vehicles, dynamic traffic noise models generally use a microscopic traffic simulation tool to simulate traffic flow [20-25].

A roundabout is a common form of traffic organization at the intersection of two roads. The complexity of traffic conditions makes the calculation of traffic noise near a roundabout challenging. Some studies have been devoted to the modelling and analysis of traffic noise at roundabouts, including the statistical analysis of traffic noise at roundabouts [26], noise emissions at roundabouts [27], static calculation models $[28,29]$ and dynamic simulation methods [30-33]. At present, dynamic simulation methods have achieved good results in predicting traffic noise at roundabouts [33]. Many dynamic traffic noise models use microscopic traffic simulation software as "Paramics" to obtain dynamic traffic flow parameters $[23,24,33]$. The cellular automata traffic flow model is a simple and effective traffic flow simulation method [34]. It uses simple evolution rules to simulate complex traffic phenomena. In recent years, there have been many reports on the use of cellular automata models to analyse the laws of traffic flows [35-37]. Several effective cellular automata models have been established to assess complex traffic flows at roundabouts [38-42], but the cellular automaton model is rarely mentioned in traffic noise dynamic modelling. Using the simple evolution rules of the cellular automaton model to realize dynamic traffic noise modelling can simplify the calculation of dynamic traffic noise, and thus this is a new method worth exploring.

The goal of this paper is to explore a new method for dynamic traffic noise modelling at roundabouts using a cellular automaton traffic flow model. This method uses a two-lane cellular automaton traffic flow model to simulate the traffic conditions at a roundabout and uses a probability distribution model to calculate the real-time noise emissions of each vehicle. In this way, this method can obtain indicators such as instantaneous sound level, hourly equivalent sound level, and statistical sound level at roundabouts and can be used to analyse the relationships between traffic flow parameters and the spatial distribution of noise emissions. The remainder of paper is organized as follows. A two-lane cellular automaton traffic flow model for a roundabout is proposed in Section 2. A dynamic traffic noise simulation model and its calculation process are given in Section 3. Section 4 presents the calculation results of the model and discusses the distribution of traffic noise at roundabouts. Finally, some conclusions are offered in Section 5 .

\section{Cellular automaton traffic flow model at roundabout}

\subsection{Basic model}

According to the vehicle operating characteristics of a roundabout, a two-lane roundabout cellular automaton

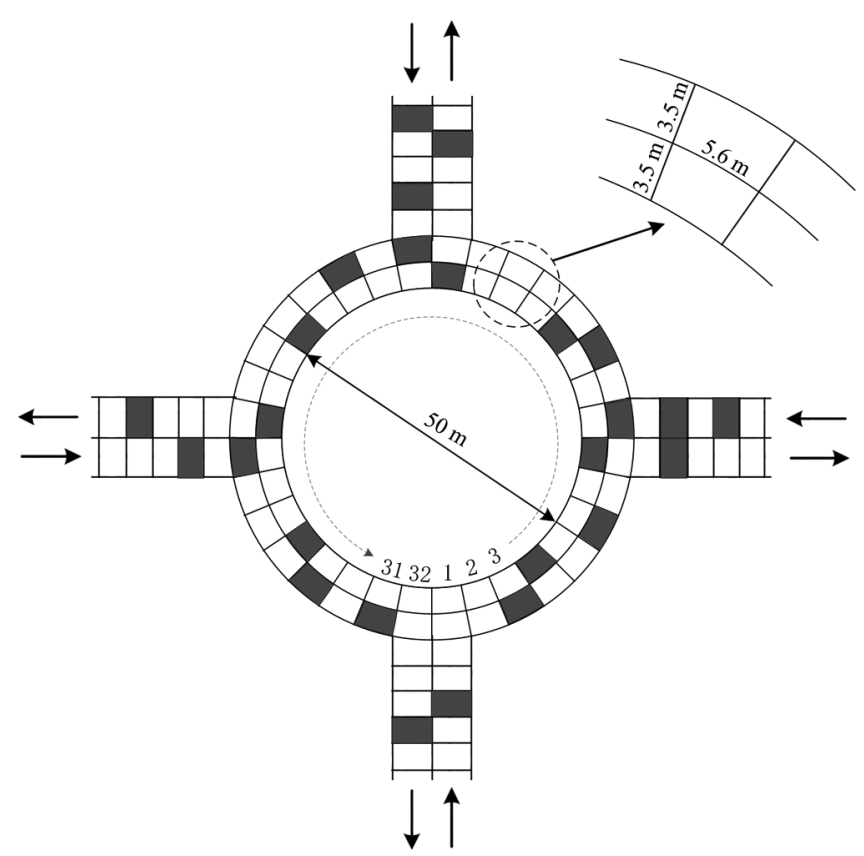

Figure 1. Schematic diagram of the cellular automaton traffic flow model for two-lane roundabouts.

traffic flow model, as shown in Figure 1, is constructed. The loop includes an outer ring and an inner ring, each represented by 32 cells. The inner diameter of the simulated roundabout is $50 \mathrm{~m}$, the width of each lane is $3.5 \mathrm{~m}$, and the length of each cell is approximately $5.6 \mathrm{~m}$. There are 4 entrances and exits at the roundabout, each of which is one-lane and is represented by 12 cells. The cell is represented by a multidimensional data structure and records information such as the vehicle occupancy, the vehicle type, the vehicle speed, the target exit, and the noise emission in the current state. To simulate a reasonable vehicle speed, assuming that each time step is $1 \mathrm{~s}$ and the maximum vehicle speed $v_{\max }=3 \mathrm{cell} / \mathrm{s}$, the corresponding actual vehicle speed is approximately $60 \mathrm{~km} / \mathrm{h}$. The speed of the vehicle may take four states: $0,1,2$, and 3 cells/s.

\subsection{Evolution steps}

The operating rules of the vehicle are established based on the classic NaSch model [34]. During step $t \rightarrow t+1$, the vehicles in the model travel in four steps: acceleration, deceleration, random slowing, and movement. Here $t$ is a discrete time step. In the calculations in this article, $t$ is expressed in seconds.

Step 1: acceleration. Under the condition that the front space is sufficient, the vehicle expects to drive at maximum speed, expressed as:

$$
v_{i}(t+1) \rightarrow \min \left[v_{i}(t)+1, \quad v_{i, \max }\right],
$$

where $v_{i}(t+1)$ is the speed of the $i$-th vehicle at time $t+1, v_{i}(t)$ is the speed of the $i$-th vehicle at time $t$, and $v_{i, \max }$ is the maximum speed of the $i$-th vehicle. In the calculations in this article, the speed of the vehicle is expressed in cells/s. 
Step 2: deceleration. When the current space is insufficient, to avoid collision with the preceding vehicle, deceleration measures are taken, which means:

$$
v_{i}(t+1) \rightarrow \min \left[v_{i}(t), \quad d_{i, F}\right],
$$

where $d_{i, F}$ is the distance between the $i$-th vehicle and the vehicle in front, that is, the number of empty cells between the two vehicles.

Step 3: random slowing. To reflect the deceleration caused by some uncertain factors, set $p$ to the random slowing probability. When $p$ occurs, there are:

$$
v_{i}(t+1) \rightarrow \max \left[v_{i}(t)-1, \quad 0\right] .
$$

Step 4: movement. The vehicle travels at the adjusted speed and is expressed as:

$$
x_{i}(t+1) \rightarrow x_{i}(t)+v_{i}(t+1),
$$

where $x_{i}(t+1)$ is the cell number of the $i$-th vehicle at time $t+1$, represented by a positive integer, and $x_{i}(t)$ is the cell number of the $i$-th vehicle at time $t$.

\subsection{Lane change rules}

The ring road adopts a two-lane model, and vehicles can change lanes under certain conditions. For a vehicle to change lane, three conditions must be met: (a) the vehicle cannot drive at the desired speed on the current lane; (b) the driving conditions on the side lane are better than the current lane; (c) the current lane change will not cause a collision. At the same time, if the distance between the vehicle and the target exit is less than 8 cells, it will no longer change lane to the left. In this way, the lane change rules can be expressed as:

$$
\begin{gathered}
L \rightarrow R:\left\{\begin{array}{c}
d_{i, F}<\min \left[v_{i}(t)+1, \quad v_{i, \max }\right] \\
d_{i, \mathrm{RF}}>d_{i, F} \\
d_{i, \mathrm{RB}}>v_{\text {max }}
\end{array},\right. \\
R \rightarrow L:\left\{\begin{array}{c}
d_{i, F}<\min \left[v_{i}(t)+1, \quad v_{i, \max }\right] \\
d_{i, \mathrm{LF}}>d_{i, F} \\
d_{i, \mathrm{LB}}>v_{\max } \\
d_{i, \mathrm{Exit}} \geq 8
\end{array}\right.
\end{gathered}
$$

where $d_{i, \mathrm{RF}}, d_{i, \mathrm{RB}}, d_{i, \mathrm{LF}}$, and $d_{i, \mathrm{LB}}$ represents the number of empty cells between the current vehicle to the front/ behind vehicle on the right/left lane, and $d_{i \text {,Exit }}$ represents the number of cells from the current vehicle to the target exit. When the vehicle meets the lane change conditions, the lane change will be performed with a certain probability and before the four steps described in the previous section.

\subsection{Other driving rules}

We have the following operational rules for the vehicles in the model:
1. When the vehicle on the entrance lane cell approaches the outer ring, if the cell in front of the vehicle is empty, the vehicle moves forward one cell into the outer ring with a certain probability; otherwise, the vehicle will wait for the next gap.

2. When the vehicle on the ring road approaches the exit (less than 4 cells from the exit), the vehicle is preferentially driven in the outer ring to drive out of the roundabout. If the vehicle is in the inner ring, it stops if necessary and then finds the right time to change lanes to the outer ring.

3. If vehicles on the inner ring, the outer ring, and the entrance lane wish to occupy the same cell at the next time step, the vehicle on the outer ring takes precedence, the vehicle on the inner ring takes the second priority, and the vehicle at the entrance takes the third priority.

4. At each time step, when the first cell of the entrance lane is empty, a new vehicle will enter the system with a certain probability, and $\alpha$ represents the probability of vehicle occurrence. When the vehicle reaches the last cell in the exit lane, the vehicle will exit the system and be logged off.

\section{Traffic noise simulation method}

\subsection{Noise calculation model}

This paper only discusses the emission and distribution of traffic noise in a small area near a roundabout, ignores the influence of obstacles and air absorption, and only considers the noise emission of the vehicles and the distance attenuation. Every vehicle on the road is considered a point source, so the sound pressure level of the $i$-th time step at the receiving point that is emitted by the $j$-th vehicle can be expressed as:

$$
L_{i, j}=L_{0}+L_{D(i, j)},
$$

where $L_{0}$ denotes the sound pressure level of a single vehicle measured at a standard distance and can be considered a vehicle noise emission model and $L_{D(i, j)}$ denotes the distance attenuation.

The distance attenuation can be expressed as:

$$
L_{D(i, j)}=10 \log _{10} \frac{d_{0}^{2}}{d_{i, j}^{2}}=10 \log _{10} \frac{d_{0}^{2}}{\left(x_{i, j}-x_{0}\right)^{2}+\left(y_{i, j}-y_{0}\right)^{2}},
$$

where $d_{0}$ denotes the reference distance when measuring the noise emission of a single vehicle, which is $7.5 \mathrm{~m}$ in the Chinese Standard "GB 1495-2002" [43], $d_{i, j}$ denotes the distance from the vehicle to the receiving point, $x_{i, j}$ and $y_{i, j}$ denote the coordinates of the vehicle, and $x_{0}$ and $y_{0}$ denote the coordinates of the receiving point.

By summing the sound energy of each vehicle at a time step, we can obtain the instantaneous sound level:

$$
L_{i}=10 \log _{10}\left(\sum_{j=1}^{m_{i}} 10^{0.1 L_{i, j}}\right),
$$


where $m_{i}$ is the number of vehicles on the road at the $i$-th time step.

After simulating $t$ time steps, the noise energy at the receiving point is averaged over time to obtain the equivalent sound level $\left(L_{\mathrm{eq}}\right)$, which is expressed as,

$$
L_{\mathrm{eq}}=10 \log _{10} \frac{\sum_{i=1}^{t} 10^{0.1 L_{i}}}{t} .
$$

\subsection{Noise emission of a single vehicle}

In a previous work, we carried out experimental measurements on the noise emissions of a single vehicle [44]. The experimental site was set up in accordance with the Chinese standard GB 1495-2002 (limits of external noise of an accelerating vehicle and relevant measurement methods) [43]. The traffic on the experimental road was sufficiently light, and there were no obvious sound obstacles within $50 \mathrm{~m}$. The sound level meters were placed $1.2 \mathrm{~m}$ above the ground and $7.5 \mathrm{~m}$ from the traffic lane on each side of the road, and a speedometer was used to record the speed of the vehicle passing by. In addition, we also measured the noise emission of the vehicle when idling. The distance between the sound level meter and the vehicle is still $7.5 \mathrm{~m}$, the vehicle remains stationary and the gearbox is neutral, but the engine is working. According to Chinese standard GA 802-2019 (Road Traffic Management-Types of Motor Vehicles) [45], vehicles are classified into three types: light vehicles, with a weight less than 2 tons; medium vehicles, with a weight of $2-12$ tons; and heavy vehicles, with a weight greater than 12 tons. A total of 3300 vehicles were measured for noise emissions, including 2429 light vehicles, 354 medium vehicles and 517 heavy vehicles.

Regression curves between the vehicle noise emission and speed can be established using the experimental measurement data, as shown in Figure 2. The noise emission regression curve obtained through the experiment is similar to the model provided in the Chinese standard JTG B03-2006 (Specifications for Environmental Impact Assessment of Highways) [46]. Previous studies have shown that it is feasible to use regression functions to calculate vehicle noise emissions in the dynamic simulation of traffic noise [23, 24, 33]. However, due to the discrete nature of the cellular automaton model, this model is more suitable to use the probability model of noise emissions instead of classic regression function models such as JTG B03-2006, ASJ-RTN, and Harmonoise. The reason is that the vehicle speed in the established cellular automaton model is discrete, with only four different values of $0,1,2$, and 3 cells/s, which represent the corresponding actual vehicle speeds of $0,20,40$, and $60 \mathrm{~km} / \mathrm{h}$. If a regression function is used, then the vehicle noise emission will have only a few different values, which cannot reflect the randomness of vehicle noise emissions. Therefore, this paper uses a probability model to replace the regression function to reflect the diversity of vehicle noise emissions.

In the calculations in this paper, we use the vehicle noise emission probability distribution model established in a (a)

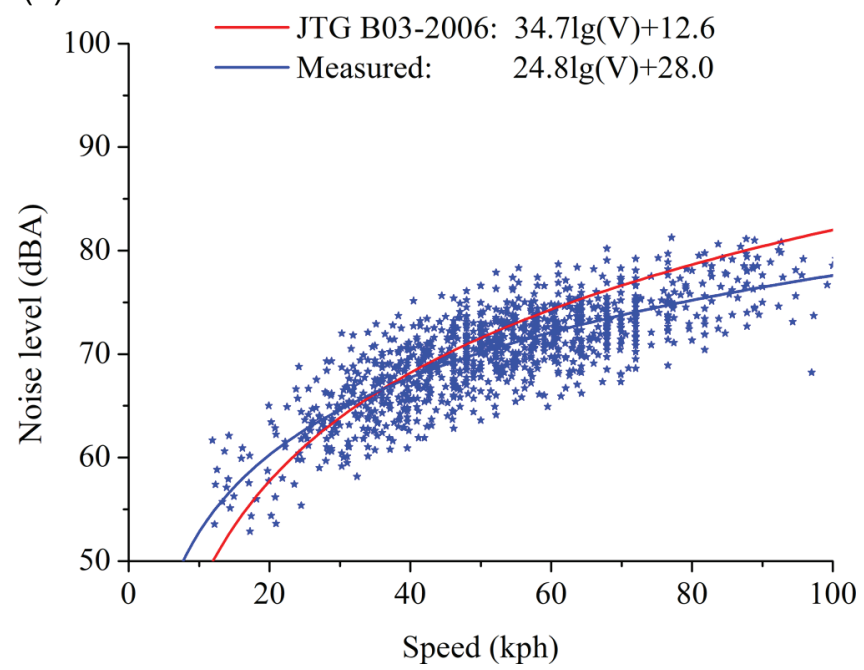

(b)

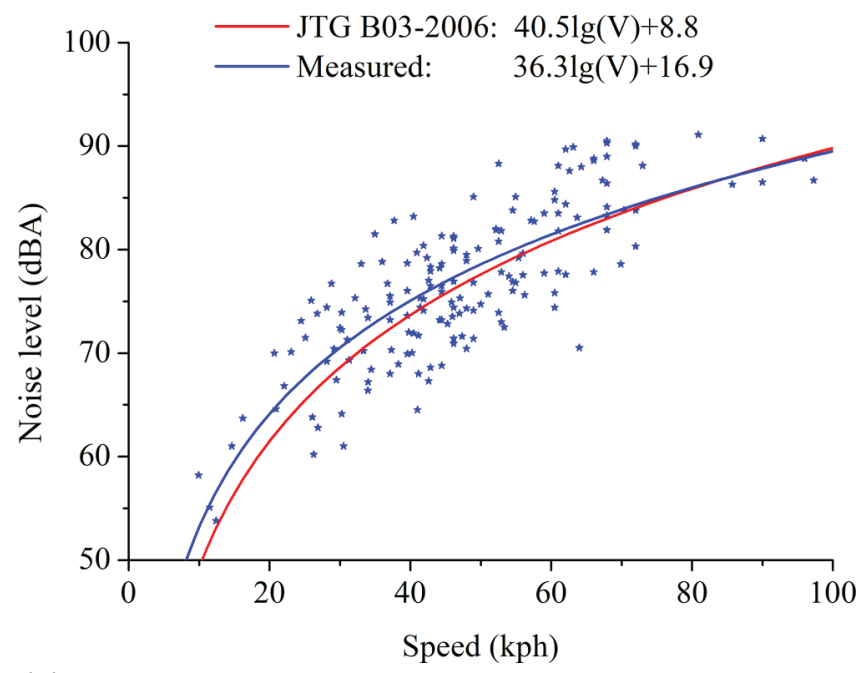

(c)

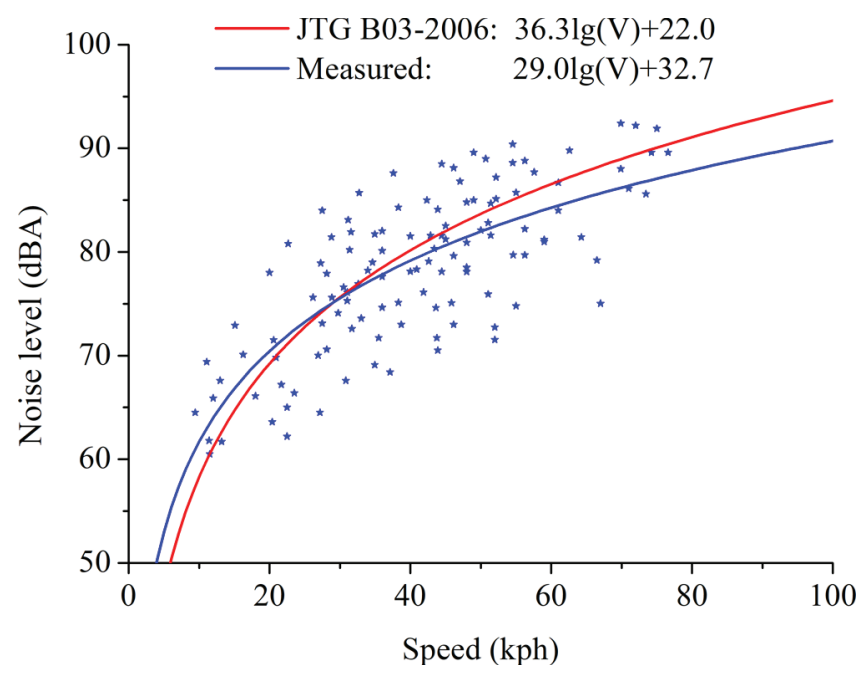

Figure 2. The regression curve between vehicle speed and noise emissions based on measured data. (a) Light vehicles; (b) medium vehicles; (c) heavy vehicles. 
Table 1. The mean and standard deviation of noise emission of a single vehicle at $7.5 \mathrm{~m}$ (in dBA).

\begin{tabular}{|c|c|c|c|c|c|c|}
\hline \multirow[t]{2}{*}{ Speed $(\mathrm{km} / \mathrm{h})$} & \multicolumn{2}{|c|}{ Heavy vehicles } & \multicolumn{2}{|c|}{ Medium vehicles } & \multicolumn{2}{|c|}{ Light vehicles } \\
\hline & $\mu$ & $\sigma$ & $\mu$ & $\sigma$ & $\mu$ & $\sigma$ \\
\hline 0 & 63.3 & 4.52 & 58.5 & 4.26 & 53.8 & 3.04 \\
\hline $0-20$ & 72.6 & 7.48 & 62.7 & 6.36 & 57.5 & 4.68 \\
\hline $20-50$ & 78.0 & 4.97 & 72.9 & 4.78 & 66.5 & 3.88 \\
\hline $50-100$ & 80.7 & 5.35 & 78.5 & 6.13 & 72.1 & 3.23 \\
\hline
\end{tabular}

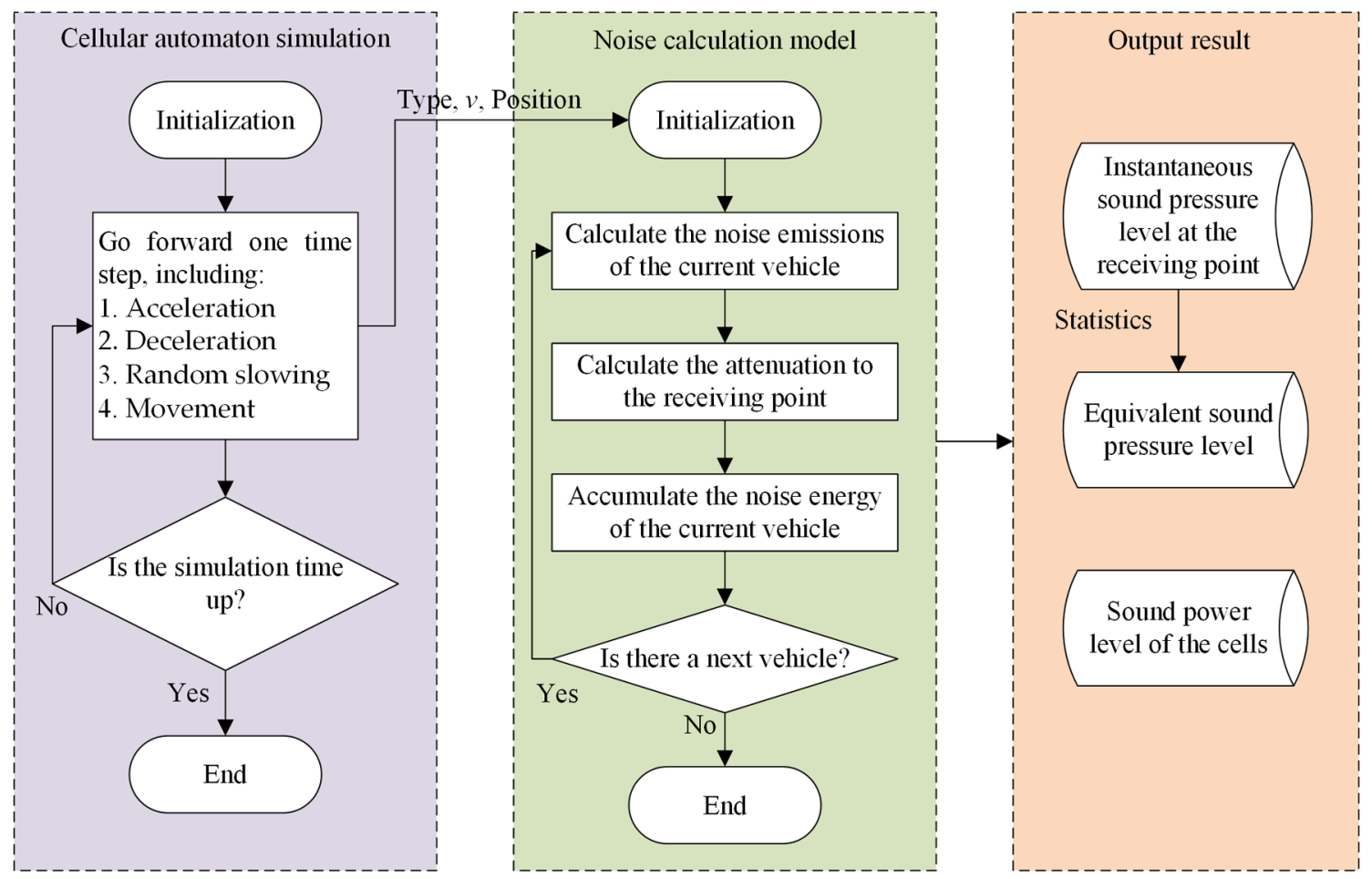

Figure 3. The logical framework diagram of traffic noise dynamic simulation includes three parts: cellular automaton traffic flow simulation, dynamic traffic noise calculation, and result output.

previous work [44]. The following is a brief description of the method of establishing the probability distribution model; see Ref. [44] for details. For each vehicle type, the collected vehicle noise emission data were divided into four groups: idle speed, $0-20 \mathrm{~km} / \mathrm{h}, 20-50 \mathrm{~km} / \mathrm{h}$ and more than $50 \mathrm{~km} / \mathrm{h}$. The normal distribution test was performed on each set of noise emission data, and it was found that each set of data satisfies the assumption of a normal distribution. Therefore, for vehicles in each speed range, their noise emissions can be represented by a normal distribution function, which is represented as $L_{0}-N\left(\mu, \sigma^{2}\right)$. Table 1 shows the $\mu$ and $\sigma$ values obtained by the experiment for the three types of vehicles at four speed grades. In the calculation of this model, first determine which speed range the vehicle speed belongs to and then generate a normally distributed random number according to the parameters in Table 1 to represent the instantaneous noise emission of the vehicle.

\subsection{Simulation process}

As shown in Figure 3, the established cellular automaton traffic flow model and traffic noise calculation model are combined to dynamically simulate the traffic noise at the roundabout. First, the cellular automaton model is used to simulate the traffic flow at the roundabout. In each step forward, the type, speed, and position of all vehicles on the road in the current state are output to the traffic noise calculation model. Then, the noise emissions of each vehicle are generated, and the propagation attenuation of the noise is calculated to obtain the current instantaneous sound level at the receiving point. In this way, the instantaneous sound level of each step is calculated. After a period of simulation, the dynamic changes in noise can be analysed based on a series of obtained instantaneous sound levels, and noise indicators such as equivalent sound level and statistical sound level can be calculated. 


\section{Cells}

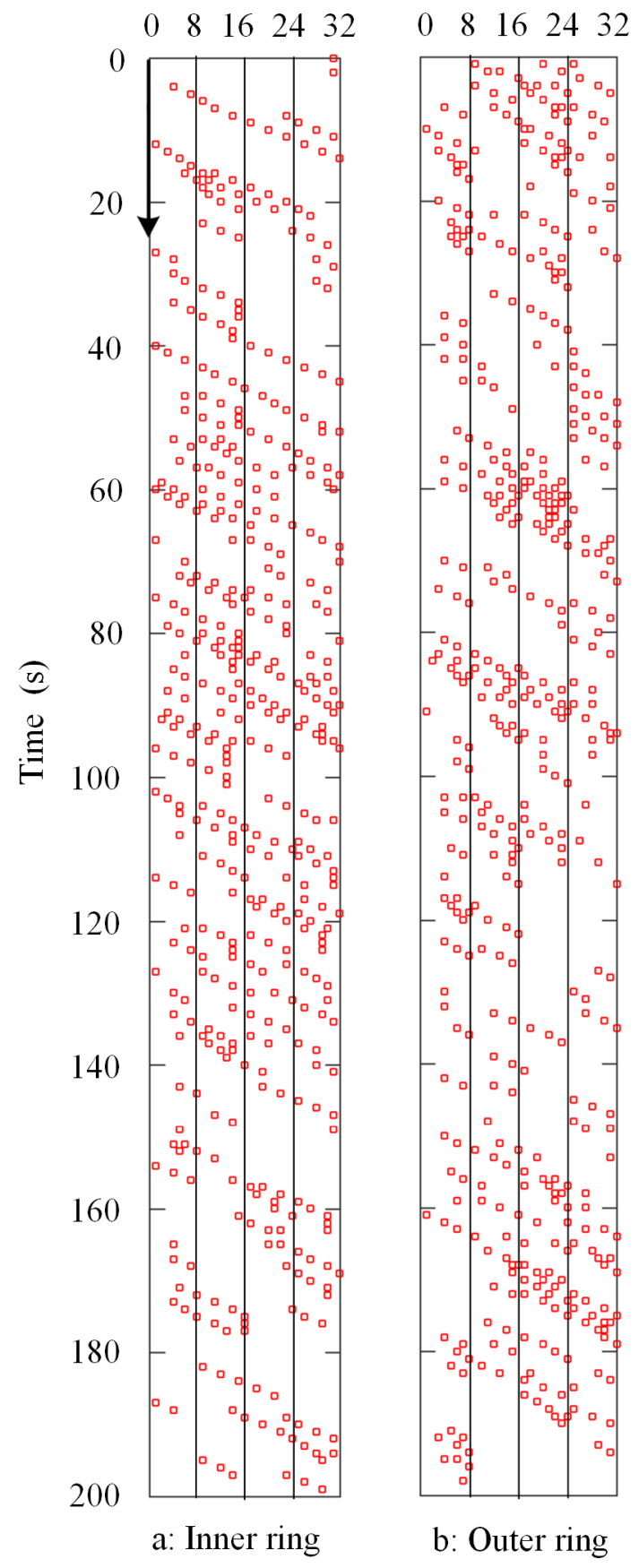

Figure 4. Time-space plots for the inner ring and outer ring with $\alpha=0.05$ and $Q \approx 720 \mathrm{veh} / \mathrm{h}$.

The calculation method and process described above were written into a $\mathrm{C}$ language program to simulate the traffic noise at roundabouts. To observe the change in traffic flow and traffic noise during the process of $\alpha$ increasing from 0.01 to 0.2 , for each level of $\alpha, 5000$ simulation steps were performed, and the last 3600 steps were taken as valid data for statistical analysis. In all simulations, the vehicle occurrence probability $\alpha$ at each entrance is equal, and the proportion of all vehicles turning right, going straight, and turning left is $1 / 3$. The ratio of heavy,

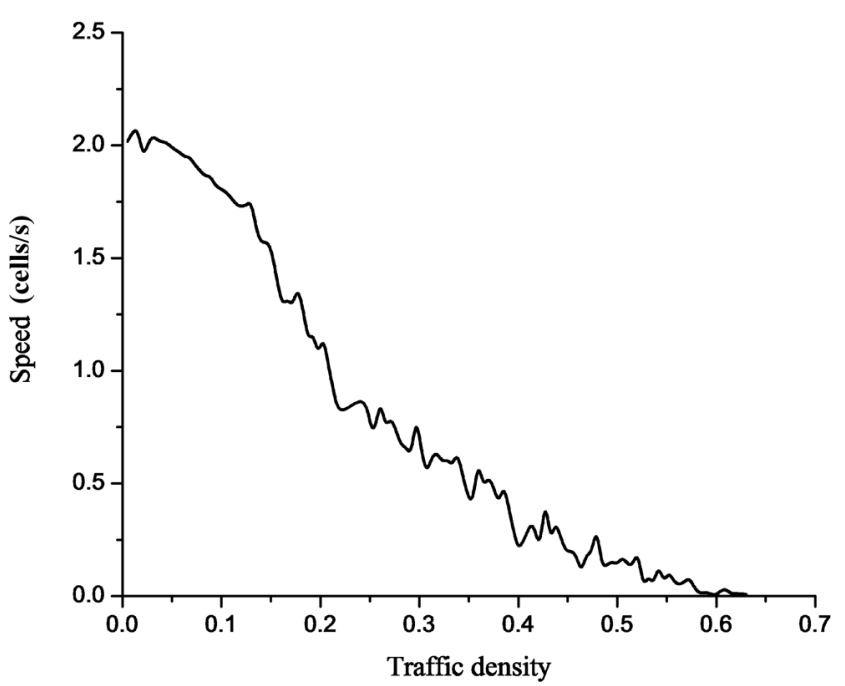

Figure 5. The relationship between traffic density and average speed at the roundabout obtained by simulation.

medium, and light vehicles is set to 0.2 : $0.1: 0.7$, and the random slowdown probability $p$ is set to 0.1 . The simulated roundabout is completely flat, and the vehicle noise emission is not affected by the slope. At each step of the simulation, data such as cell occupancy, speed, and noise emissions are recorded.

\section{Results and discussion}

\subsection{Traffic flow simulation}

The vehicle running dynamic data on the ring is the output, and the 200-second data when $\alpha=0.05$ are randomly drawn into time-space plots, as shown in Figure 4. The inner ring lane and the outer ring lane are each composed of 32 cells. The cell numbers are shown in Figure 1. The numbers of the four exit cells on the outer ring are 8 , 16,24 , and 32 , which are marked with vertical lines in Figure 4 . The time-space plot of the inner ring appears to be orderly, indicating that the vehicles on the inner ring run smoothly and are less disturbed by entrances and exits. Nevertheless, some vehicles may stop and wait at positions 2-3 cells before each exit. The reason is that the vehicles need to leave the roundabout and wait for the opportunity to change to the outer ring. In contrast, the time-space plot of the outer ring looks chaotic, and vehicles are prone to congestion under the influence of entrances and exits. The midway joining and leaving of vehicles are another cause of chaos in the time-space plot of the outer ring.

We use the ratio of the number of nonempty cells to the total number of cells to represent the traffic density. The average speed of all cells and the traffic density of the roundabout are calculated at different traffic volume levels, and the results are shown in Figure 5. With increasing traffic density, the average speed approximately linearly decreases, which is in accordance with the general law of traffic engineering. The maximum speed of the model is 


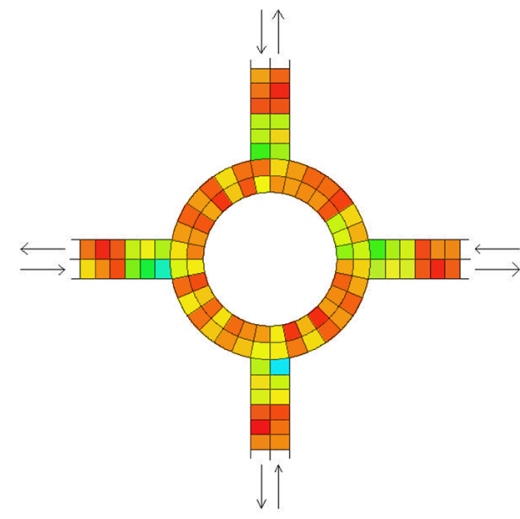

(a)

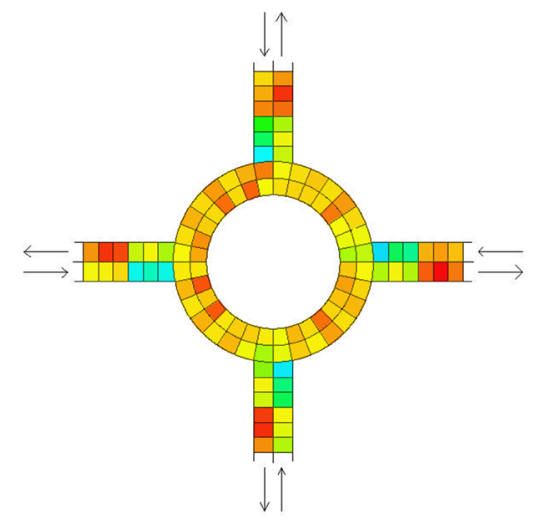

(b)

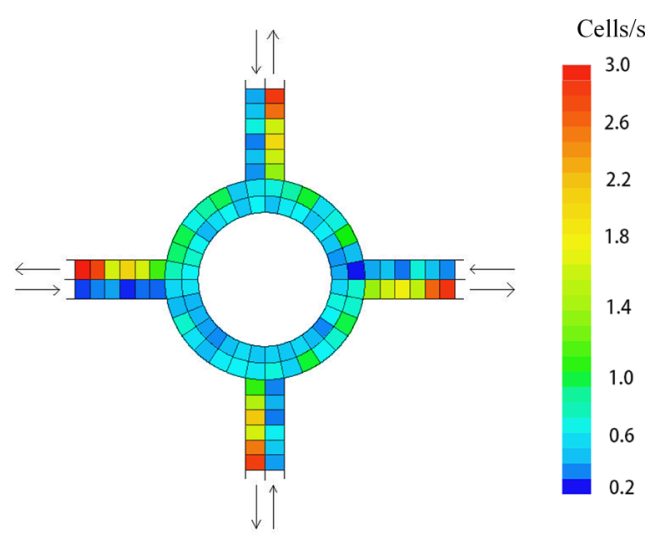

(c)

Figure 6. The average speed distribution of the cells at the roundabout obtained by simulation. (a) $\alpha=0.01$; (b) $\alpha=0.05$; (c) $\alpha=0.1$.

3 cell/s, but when the traffic volume is light, the average speed is approximately $2.1 \mathrm{cell} / \mathrm{s}$. The reason is that the vehicle driving states change frequently at the roundabout, and the average speed is affected by factors such as vehicles changing lanes, random slowing, and decelerating when entering and exiting the roundabout. When the traffic density reaches more than 0.6 , the traffic at the roundabout becomes congested, and the average speed is almost 0 . It should be noted that the traffic density of the exit lane is still low at this time, and the traffic density on the ring road is close to 0.8 .

During the simulation, the speed of the vehicle on each cell at each instant is recorded. After $1 \mathrm{~h}(3600 \mathrm{~s})$ of simulation, the average speed of the vehicle on each cell can be counted. When $\alpha$ is $0.01,0.05$, and 0.1 , the corresponding traffic volumes are approximately 144,720 , and $1440 \mathrm{veh} / \mathrm{h}$, which represent three levels of traffic volume: low, medium, and high. Figure 6 shows the cell average speed distribution under three traffic levels. Consistent with the results in Figure 5, the average speed of the cells decreases significantly with the increase in traffic. The speed of the cells near the entrance and exit on the ring road decreases significantly. As vehicles need to ensure safety before entering the ring road, the speed of several cells in front of each entrance also decreases significantly. The cell speed of the exit lane is significantly higher than that of the entrance lane. At high traffic levels, even if the average speed of the entrance and ring roads has dropped to less than $1 \mathrm{cell} / \mathrm{s}$, vehicles in the exit lane can still leave the roundabout at a speed of more than 2 cell/s. From the above data, the simulation results of the proposed model for traffic at roundabouts are reasonable. Next, we will discuss the emission and distribution of traffic noise on this basis.

\subsection{Distribution of sound power level at roundabouts}

In previous studies, to simplify the calculation of noise at roundabouts, it was often assumed that the intensity of the sound sources on the roundabout was equal everywhere. In fact, Figure 6 shows that the speed distribution on the ring road is not uniform, so the sound source intensity on the ring road may also be unevenly distributed. To assess this issue, we introduce the average sound power level of the cell $\left(L_{\mathrm{AWC}}\right)$ as an evaluation parameter. In the previous vehicle noise emission calculation, $L_{0}$ in Equation $(7)$ is the A-weighted sound level measured at $7.5 \mathrm{~m}$ from the vehicle. Therefore, the sound power level of the vehicle can be expressed as:

$$
L_{\mathrm{veh}}=L_{0}+10 \log _{10}\left(2 \cdot \pi \cdot 7.5^{2}\right)=L_{0}+25.5 .
$$

Then, the relative sound power of the cell at any time can be expressed as:

$$
W_{i}=\left\{\begin{array}{ll}
W_{0} \cdot 10^{0.1 \cdot L_{\mathrm{veh}},} & \text { When the cell is occupied by a vehicle } \\
0, & \text { When the cell is empty }
\end{array},\right.
$$

where $W_{o}=10^{-12}$ (Watts) - reference sound power. After simulating $t$ time steps, the average sound power level of the cell can be calculated by:

$$
L_{\mathrm{AWC}}=10 \log _{10} \frac{\sum_{i=1}^{t} W_{i}}{t} .
$$

Considering different vehicle incidence levels, the noise emission for $1 \mathrm{~h}(3600 \mathrm{~s})$ is simulated, and the average sound power level of each cell is calculated according to Equation (13). The results are shown in Figure 7. It is easy to see that as the traffic volume increases, the sound power level of the cells on the ring road increases and tends to be uniform, although the average speed decreases. When the vehicle incidence $\alpha$ is $0.01,0.05$, and 0.1 , the average sound power levels of all cells on the ring road are $82.4 \mathrm{~dB}(\mathrm{~A})$, $85.3 \mathrm{~dB}(\mathrm{~A})$, and $87.6 \mathrm{~dB}(\mathrm{~A})$. Corresponding to the speed distribution (Fig. 6), the cell sound power level of the cell near the entrance and exit on the ring road is lower than that at other locations, even under heavy traffic conditions (Fig. 7c). Although the average speed is low, the sound power level at the entrance approach does not drop significantly because the entrance approach often has vehicle queuing, and the cell occupancy rate is higher than other 


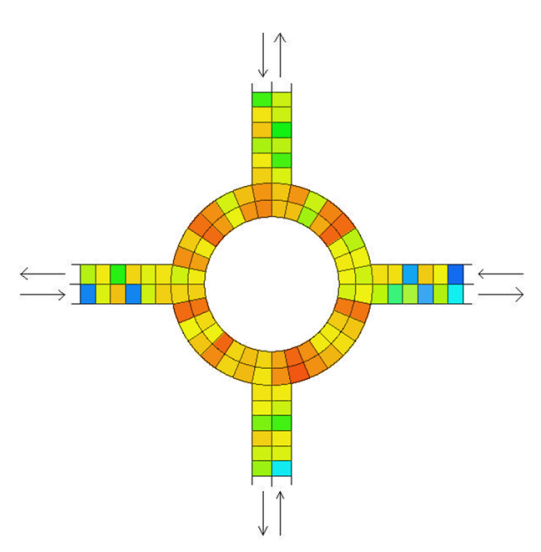

(a)

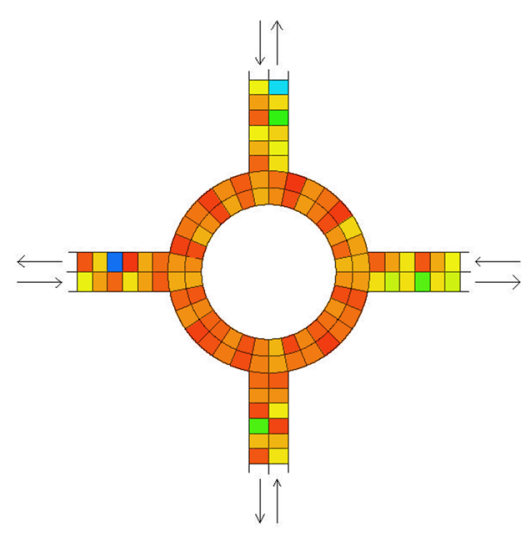

(b)

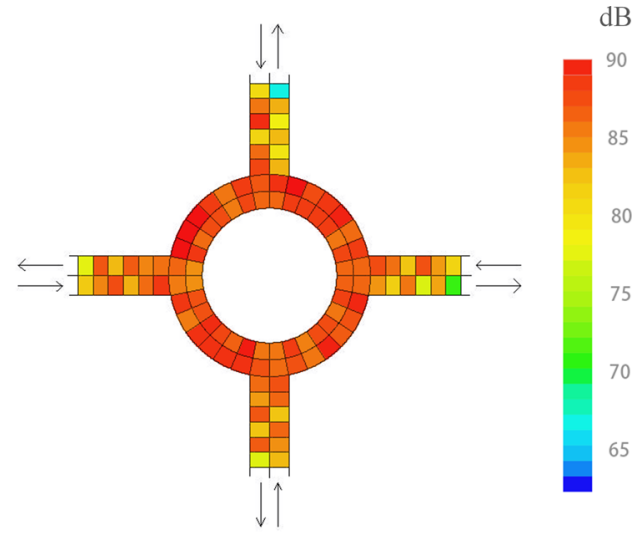

(c)

Figure 7. Hourly average sound power level distribution of cells at the roundabout obtained by simulation. (a) $\alpha=0.01 ;(\mathrm{b}) \alpha=0.05$; (c) $\alpha=0.1$.

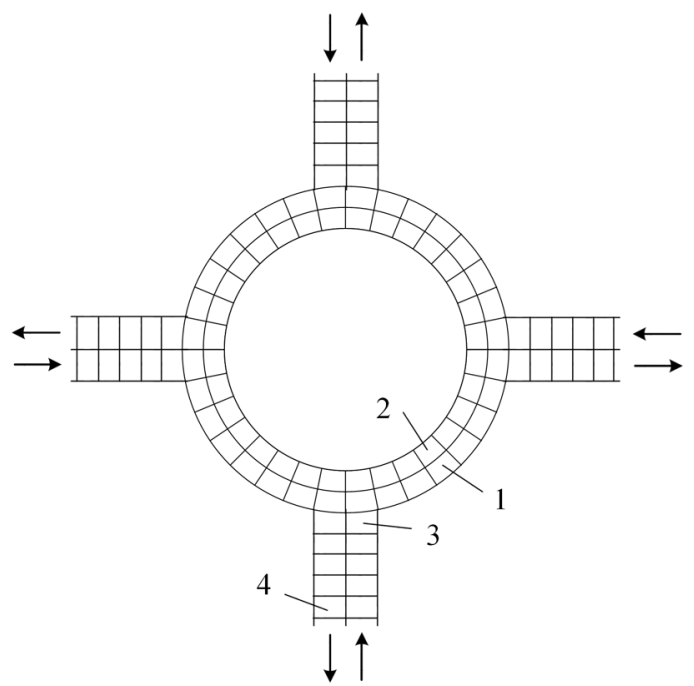

a: Locations of the cells

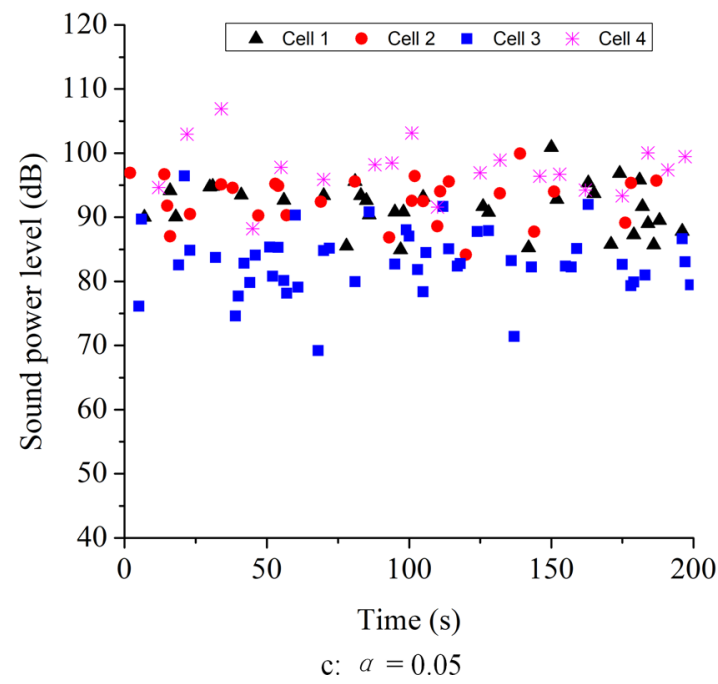

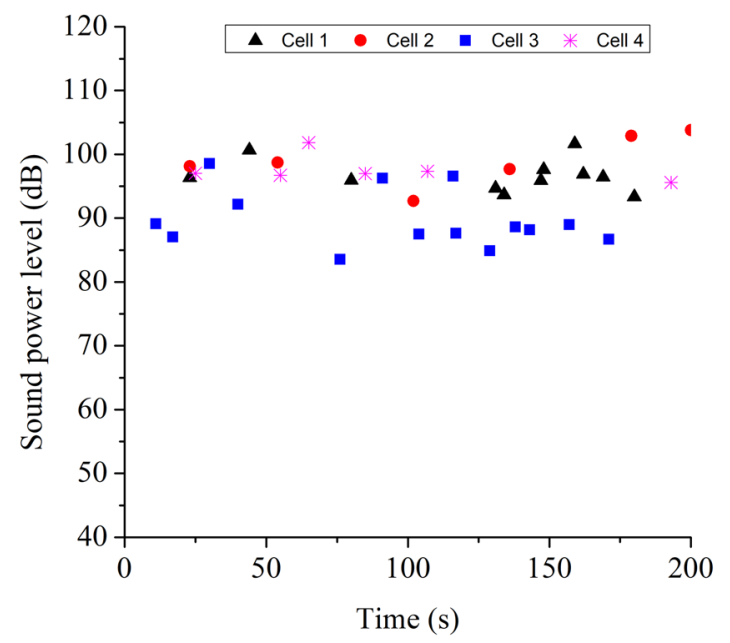

b: $a=0.01$

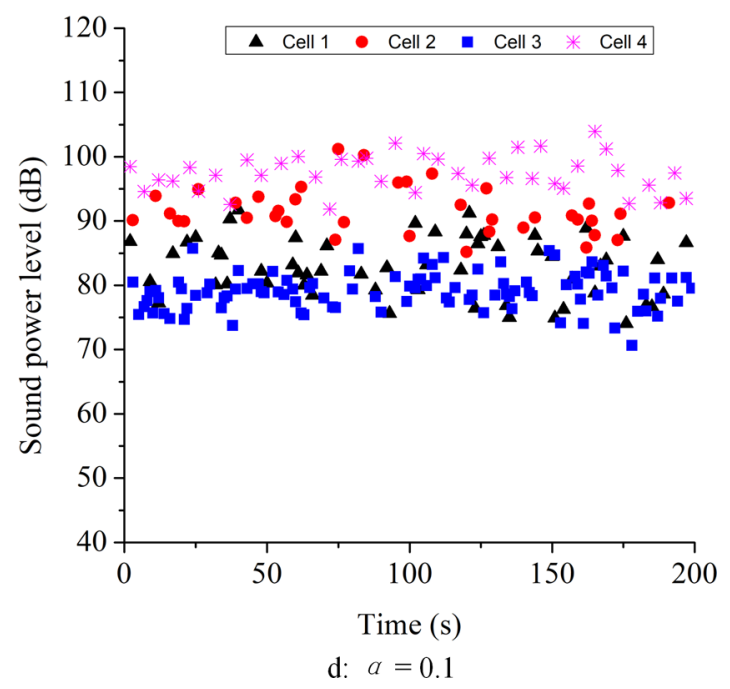

Figure 8. Comparison of sound power levels of the cells in different positions. 
locations. It should be noted that the sound power levels of several cells in each exit lane are quite different, which may be a small defect of this model. The reason is that vehicle tend to drive at the maximum speed in the exit lane, so some cells are likely to be crossed, which reduces the number of noise emissions recorded by these cells.

To further explore the differences in the sound power level of the cells at different positions, we select the instantaneous sound power level data of the cells at four different positions, as shown in Figure 8a, for comparative analysis. Positions 1-4 represent four different traffic attributes of the outer ring, inner ring, ring entrance, and exit quickly leaving. Two hundred continuous time steps were randomly selected, and the instantaneous sound power level scatter diagram of these four cells was drawn (Figs. 8b-8d). When $\alpha=0.01$, the traffic volume is small, the vehicle speed is high, and the instantaneous sound power levels of the four cells have no obvious differences. As the traffic volume increases, the instantaneous sound power levels of the four cells gradually form a stratification. When $\alpha=0.1$, the sound power level of cell 4 is the highest, cell 1 and cell 2 are the next highest, and cell 3 is the lowest. This is caused by the different speeds of the four positions. The vehicles at cell 3 often need to slow down and wait for the opportunity to enter the ring road, so the speed is the lowest. The vehicle at cell 4 is accelerating and driving away, and the vehicle speed is the highest. There is no obvious difference between the speeds of cell 1 and cell 2, and the sound power levels are similar. The number of points in the figure represents the number of times the cell emits noise and the number of times the cell is occupied by vehicles. For example, the number of scattered points of cells $1-4$ in Figure 8 is 57, 43,103 , and 39 , which can reflect that cell 3 has the highest vehicle occupancy rate, and cell 4 has the lowest.

Figure 9 shows the comparison of the average sound power levels of the cells of the inner ring and the outer ring. When the traffic volume at the roundabout is low (less than $1200 \mathrm{veh} / \mathrm{h}$ ), there is no significant difference in the average sound power level between the inner ring and the outer ring. However, when the traffic volume continues to increase, the sound power level of the inner ring is $1-2 \mathrm{~dB}$ higher than that of the outer ring. The reason is that when the traffic volume is high, the speed of vehicles on the outer ring is more affected by entrances and exits, and the speed is lower. Traffic volume and speed are the two main factors that determine traffic noise emissions, and there is a mutual restriction between them. In this example, when the traffic volume reaches more than $1700 \mathrm{veh} / \mathrm{h}$, the traffic noise emission will no longer increase due to the decrease in speed. This shows that there is an upper limit for the traffic noise emission in the system, which is consistent with the research conclusion of Ref. [33].

\subsection{Comparison with other methods}

Makarewicz et al. [29] established a static model of noise prediction for roundabouts using the principle of energy integration. Since vehicle noise emissions were not given

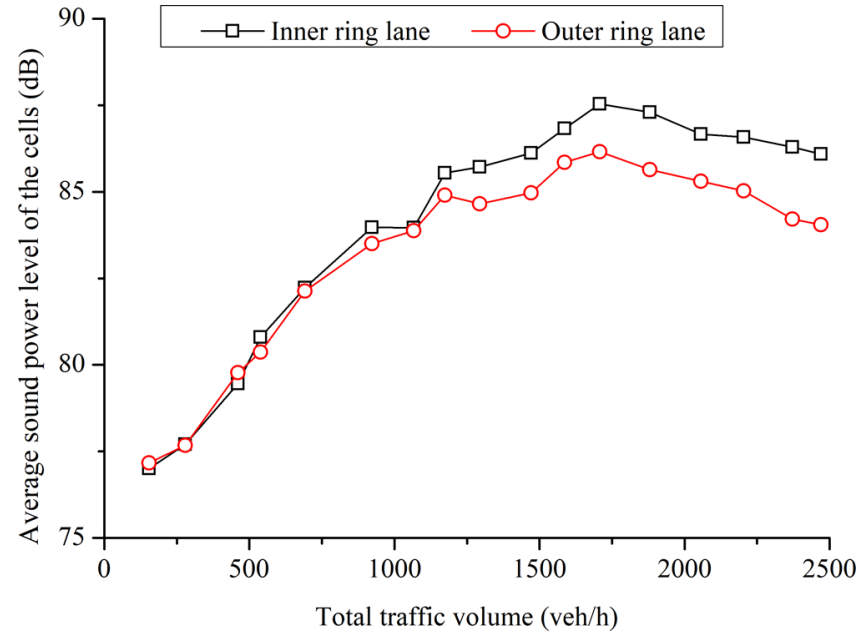

Figure 9. Comparison of the average sound power levels of the cells in the inner ring and the outer ring.

in Ref. [29], we use vehicle emissions in the Chinese standard JTG B03-2006 instead [46]. The proposed model and the static model given in Ref. [29] are used to calculate the distribution of $L_{\mathrm{eq}, 1 \mathrm{~h}}$ around the roundabout under the same traffic conditions. The traffic parameters are as follows: the vehicle occurrence rate at each entrance is 0.1 , and the corresponding traffic volume at the roundabout is approximately $1440 \mathrm{veh} / \mathrm{h}$. The probability of the vehicle turning right, going straight, and turning left around the island is $1 / 3$.

The noise distribution diagrams calculated by the two methods are shown in Figure 10. The distributions of $L_{\text {eq } 1 \mathrm{~h}}$ calculated by the two methods have little difference. At the same position, the result of this model is $2-3 \mathrm{dBA}$ higher than that of Ref. [29]. The reason is that the vehicle noise emission of this model is slightly higher than the Chinese standard JTG B03-2006 in the low-speed range. The contours of the static model (Fig. 10b) appear smoother than those of the proposed model (Fig. 10a) near the roadway. This is because the cellular automaton model is discrete, and the vehicle moves in a beating manner, but this does not affect the overall noise distribution. It should be noted that the noise contour tends to narrow at each exit, which may be inconsistent with the actual situation. The reason is that the model only considers the influence of vehicles within $\pm 100 \mathrm{~m}$ and ignores the noise of vehicles outside the range.

To test the effectiveness of the model for dynamic noise prediction, we compare the calculation results of the proposed model with the dynamic simulation method given in Ref. [33]. In Ref. [33], the authors employed microscopic traffic simulation software (Paramics) to simulate traffic and obtain the input parameters for dynamic noise calculation, and the traffic noise at a roundabout and a signalcontrolled intersection were simulated. The simulated noise values of 8 monitoring points were compared with the measured values. The results show that the simulated values are close to the measured values, which proves that the method in Ref. [33] has high accuracy. The difference is that the pro- 
(a)

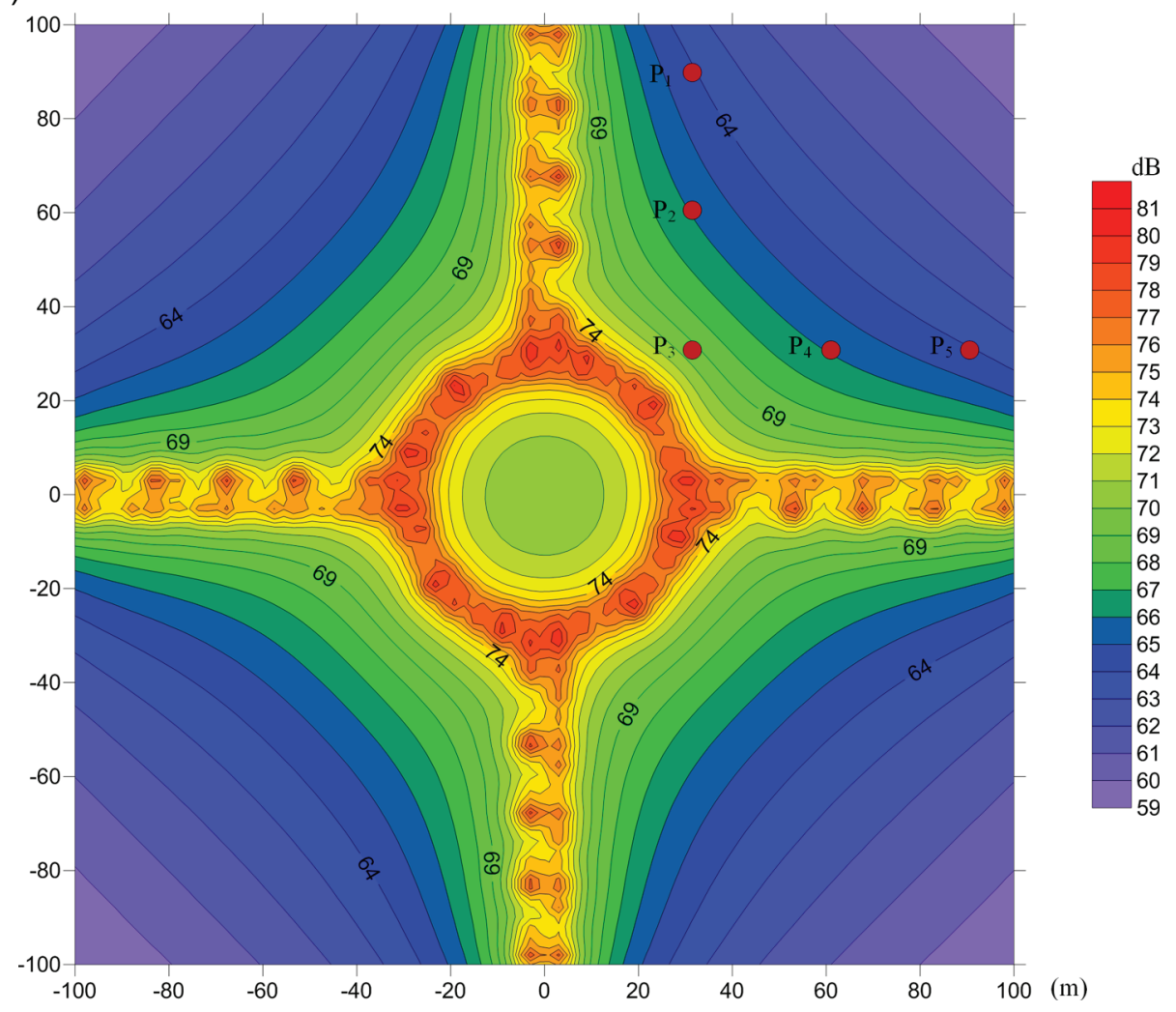

(b)

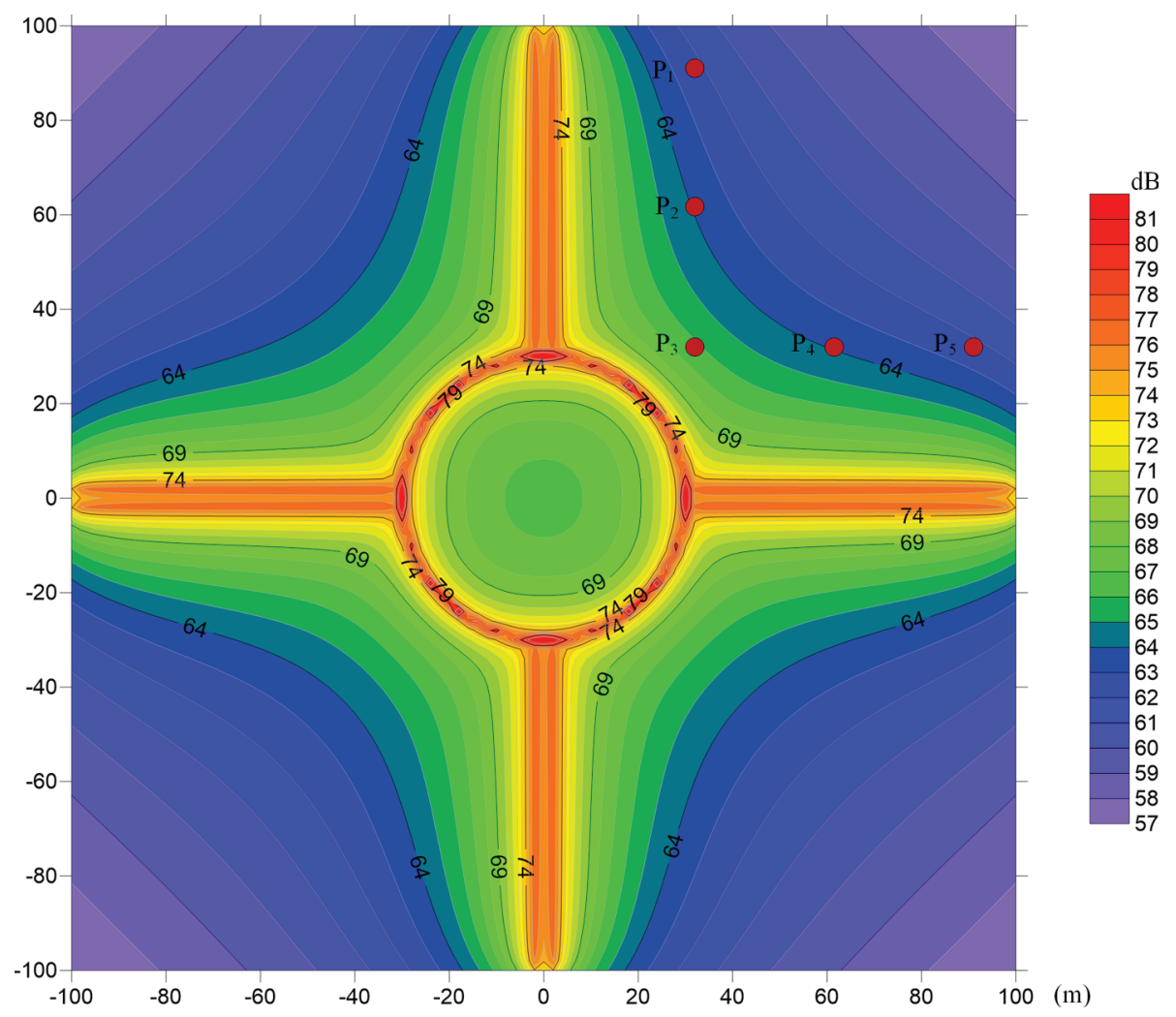

Figure 10. The simulated equivalent sound level $\left(L_{\mathrm{eq}}\right)$ distribution near the roundabout. (a) The proposed model with $\alpha=0.1$ and $Q \approx 1440 \mathrm{veh} / \mathrm{h}$; (b) the model given in Ref. [29] with $Q \approx 1440 \mathrm{veh} / \mathrm{h}$. 

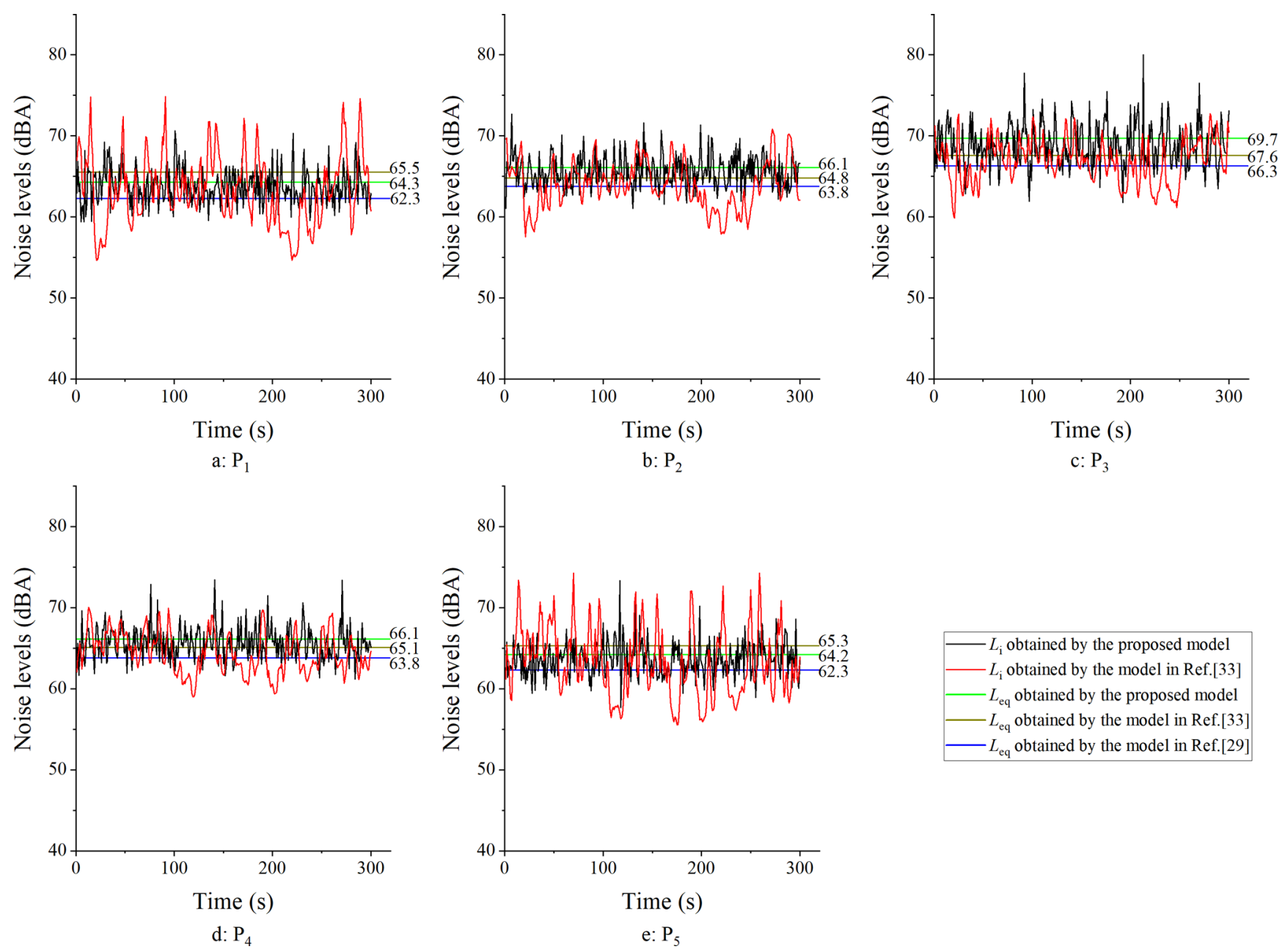

Figure 11. Comparison of simulation results between the proposed model and the models given in Refs. [29] and [33].

Table 2. Simulation results of traffic noise at positions $\mathrm{P} 1-\mathrm{P} 5$ with $Q \approx 1440 \mathrm{veh} / \mathrm{h}$ (in $\mathrm{dBA})$.

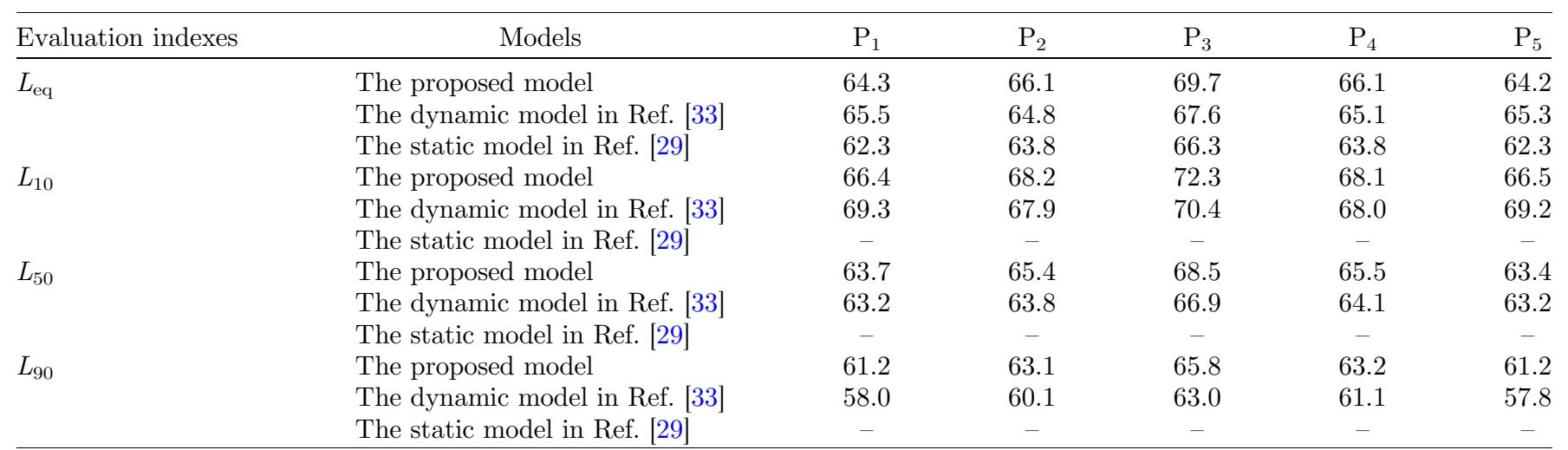

posed method uses a cellular automata traffic flow model to replace the microscopic traffic simulation software. We use these two methods to build a two-lane roundabout of the same scale, and the traffic volume is set to $1440 \mathrm{veh} / \mathrm{h}$, which is consistent with the traffic volume when $\alpha=0.1$ in this paper. Both methods use the same vehicle noise emission model and noise propagation attenuation model.
We calculate the instantaneous sound levels and the hourly equivalent sound levels of the five monitoring points P1-P5 shown in Figure 10. Figure 11 shows the instantaneous sound levels for 300 consecutive seconds and equivalent sound levels $\left(L_{\mathrm{eq}}\right)$ at the 5 monitoring points. From the comparison of the equivalent sound levels, the result of the static model given in Ref. [29] is $2-3 \mathrm{dBA}$ lower than 


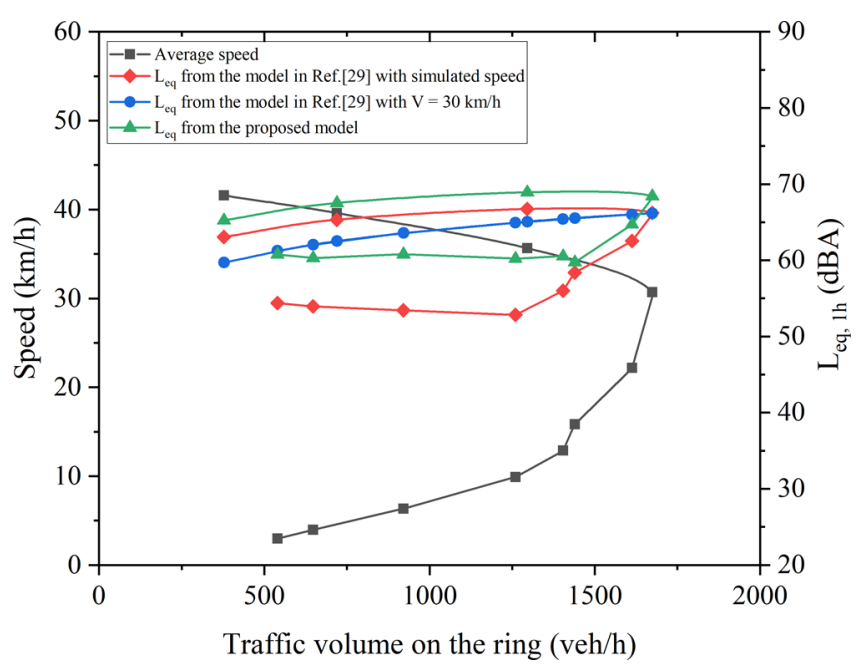

Figure 12. The relationship between the average speed and the traffic volume of the roundabout obtained by the proposed model and the relationship between $L_{\text {eq, } 1 \mathrm{~h}}$ at monitoring point P3 and the traffic volume.

the proposed model. The reason has been mentioned above: the vehicle noise emission of this model is slightly higher than the Chinese standard JTG B03-2006 in the low-speed range. The equivalent sound levels obtained by the two dynamic models (the proposed model and the model given in Ref. [33]) are close, and the average difference is $1.34 \mathrm{dBA}$. However, it should be noted that the result of the proposed model is greater at the locations close to the centre of the intersection as P2, P3 and P4 and smaller at the locations far from the centre of the intersection as P1 and P5. The simulation results given in Table 2 further illustrate this phenomenon. At P1 and P5, the difference between $L_{10}$ and $L_{90}$ obtained by the proposed model are smaller than that of the model in Ref. [33], which has a wider distribution of instantaneous sound level values, so the $L_{\text {eq }}$ calculated from the average sound energy is higher. The deeper reason may be that the speed change range of the proposed model at the four exits is smaller, and the influence of vehicles outside the simulation range is ignored, so the instantaneous sound level fluctuation range calculated by the proposed model is smaller. Judging from the curve of the instantaneous sound level, the instantaneous sound level of the proposed model jumps quickly and appears to be irregular. This is because the vehicle noise emission of the proposed model uses a probability distribution model instead of a regression model.

\subsection{The advantages and disadvantages of the model}

Compared with the static traffic noise prediction model, the advantage of the proposed model is that it contains complete traffic operation information. According to these simulated traffic data, the relationship between traffic volume and speed can be obtained, the capacity of roundabouts can be inferred, and the traffic congestion status can be analysed. For example, by continuously increasing the probability of occurrence of vehicles in the cellular automaton model and simultaneously counting the number of vehicles entering the ring and the average speed of the ring, the relationship curve between traffic volume and speed can be obtained, as shown by the black curve in Figure 12. The curve is similar to a parabola after rotation, which is consistent with the conclusion of traffic engineering. The upper part of the curve represents the noncongested state, and the speed decreases with increasing traffic volume. The lower part of the curve represents the congestion state, and the speed and traffic volume decrease as the congestion increases. It can be inferred that the traffic capacity of the roundabout is approximately $1700 \mathrm{veh} / \mathrm{h}$. Traffic volume and speed are two important parameters for traffic noise prediction, and they are not independent of each other but have a specific relationship. The static traffic noise model ignores the relationship between traffic volume and speed, which may lead to incorrect parameter inputs. Figure 12 also shows $L_{\text {eq,1h }}$ at point P3 as calculated by different methods under different traffic conditions. When the traffic is not congested, the results of the proposed model are close to those of the model given in Ref. [29]. However, when the traffic is congested, the results of the two models show a large difference. Under the same conditions of input traffic volume and speed, the result of the proposed model is $5-6$ dBA higher than that of the model given in Ref. [29]. The reason is that this model uses the same noise emission function when the vehicle speed is less than $20 \mathrm{~km} / \mathrm{h}$, while the regression model used for the model in Ref. [29] gives lower noise emissions at low speeds. It is impossible to directly determine which model is more accurate under congested traffic conditions, which requires a verification of the measured data. It should be noted that if the impact of traffic volume on speed is ignored and the speed is assumed to be constant at a certain value (such as $30 \mathrm{~km} / \mathrm{h}$ ), the static model cannot distinguish between congested and non-congested states, and the noise prediction under traffic congested states is invalid.

Compared with the general dynamic traffic noise model, the proposed model also has the advantage of fast calculation speed. The computer configuration used in this article is an Intel Core i3 $8350 \mathrm{~K} \mathrm{CPU}$ at $4.0 \mathrm{GHz}, 8 \mathrm{~GB}$ of memory, and single-threaded calculations. Under the same computer configuration conditions, the calculation time required by the proposed method is approximately $20 \mathrm{~s}$, while the method in Ref. [33] requires approximately $3 \mathrm{~min}$. This is due to the simple evolution rules of the cellular automata traffic flow model. From this perspective, the traffic noise calculation efficiency of the proposed method is higher.

The proposed model may still have some shortcomings. On the one hand, the speed of the vehicle has only four different states, so the simulation of traffic may be inaccurate. On the other hand, the noise emission model used in the proposed model was measured under uniform speeds without considering the impact of vehicle acceleration on noise. This may cause some errors on the roads that are significantly accelerated. These problems will be improved in future research work. 


\section{Conclusion}

This paper presents a cellular automaton traffic flow model for a two-lane roundabout. On this basis, a vehicle noise emission probability model is integrated into the traffic flow simulation to realize the dynamic simulation of traffic noise at roundabouts. During the operation of the cellular automaton, the dynamic simulation of traffic noise is realized by loading the vehicle noise emission model and the noise propagation attenuation calculation model. The proposed method can not only calculate the noise at the receiving point near a roundabout but also reflect the dynamic changes in noise and the characteristics of road noise emissions. The effectiveness of the proposed model is verified by comparison with the current traffic noise prediction model at roundabouts. In summary, the method proposed in this paper may have good application prospects in traffic and noise analysis at roundabouts.

\section{Acknowledgments}

The work described in this paper was funded by the China National Key R\&D Program, (No. 2020YFB1600400); the Natural Science Foundation of Guangdong Province, China (Nos. 2019A1515011779 and 2018A030313947); the Foundation for Distinguished Young Talents in Higher Education of Guangdong, China (No. 2019KQNCX066); and the Science and Technology Planning Project of Guangzhou, China (Nos. 201803030041 and 201905010007). Comments and suggestions from the reviewers and editor are highly appreciated.

\section{References}

1. M. Basner, W. Babisch, A. Davis, M. Brink, C. Clark, S. Janssen, S. Stansfeld: Auditory and non-auditory effects of noise on health. The Lancet 383, 9925 (2014) 1325-1332.

2.H.M.E. Miedema, C.G.M. Oudshoorn: Annoyance from transportation noise: relationships with exposure metrics DNL and DENL and their confidence intervals. Environmental Health Perspectives 109 (2001) 409-416.

3. K. Sygna, G.M. Aasvang, G. Aamodt, B. Oftedal, N.H. Krog: Road traffic noise, sleep and mental health. Environmental Research 131 (2014) 17-24.

4.P. Lercher, G.W. Evans, M. Meis: Ambient noise and cognitive processes among primary schoolchildren. Environment and Behavior 35 (2003) 725-735.

5. F. Minichilli, F. Gorini, E. Ascari, F. Bianchi, A. Coi, L. Fredianelli, G. Licitra, F. Manzoli, L. Mezzasalma, L. Cori: Annoyance judgment and measurements of environmental noise: A focus on Italian secondary schools. International Journal of Environmental Research and Public Health 15, 2 (2018) 208.

6. D. Vienneau, C. Schindler, L. Perez, N. Probst-Hensch, M. Röösli: The relationship between transportation noise exposure and ischemic heart disease: A meta-analysis. Environmental Research 138 (2015) 372-380.

7. R. Guski, D. Schreckenberg, R. Schuemer: WHO environmental noise guidelines for the European region: A systematic review on environmental noise and annoyance. International Journal of Environmental Research and Public Health 14 (2017) 1539.
8. M. Basner, S. McGuire: WHO environmental noise guidelines for the European region: A systematic review on environmental noise and effects on sleep. International Journal of Environmental Research and Public Health 15 (2018) 519.

9. P. Lercher, B. De Coensel, L. Dekonink, D. Botteldooren: Community response to multiple sound sources: Integrating acoustic and contextual approaches in the analysis. International Journal of Environmental Research and Public Health 14 (2017) 663.

10. J. Peng, J. Parnell, N. Kessissoglou: Spatially differentiated profiles for road traffic noise pollution across a state road network. Applied Acoustics 172 (2021) 1-9. https://doi.org/ 10.1016/j.apacoust.2020.107641.

11. J. Wunderli, R. Pieren, M. Habermacher, D. Vienneau, C. Cajochen, N. Probst-Hensch, M. Röösli, M. Brink: Intermittency ratio: A metric reflecting short-term temporal variations of transportation noise exposure. Journal of Exposure Science \& Environmental Epidemiology 26 (2016) 575-585. https://doi.org/10.1038/jes.2015.56.

12. B. De Coensel, A.L. Brown, D. Tomerini: A road traffic noise pattern simulation model that includes distributions of vehicle sound power levels. Applied Acoustics 111 (2016) 70-178. https://doi.org/10.1016/j.apacoust.2016.04.010.

13. J.L. Rochat, G.G. Fleming: Validation of FHWA's Traffic Noise Model $^{\circledR}$ (TNM): Phase 1. Department of Transportation, Washington DC, USA, 2002.

14. G. Fleming, A. Rapoza, C. Lee: Development of National Reference Energy Mean Emission Levels for the FHWA Traffic Noise Model, Version 1.0. Publication No. DOT-VNTSCFHWA-96-2, Office of Engineering and Highway Operations Research and Development, Washington, DC, 2005.

15. S. Kephalopoulos, M. Paviotti, F. Anfosso-Ledee: Common Noise Assessment Methods in Europe (CNOSSOS-EU) EUR 25379 EN. Publications Office of the European Union, Luxembourg, 2012.

16. Sh. Givargisa, M. Mahmoodi: Converting the UK calculation of road traffic noise (CORTN) to a model capable of calculating $\mathrm{L}_{\mathrm{Aeq}, 1 \mathrm{~h}}$ for the Tehran's roads. Applied Acoustics 69 (2008) 1108-1113.

17. S. Sakamoto: Road traffic noise prediction model "ASJ RTNModel 2018": Report of the Research Committee on Road Traffic Noise. Acoustical Science and Technology 41, 3 (2020) 529-589.

18. A. Can, P. Aumond: Estimation of road traffic noise emissions: The influence of speed and acceleration. Transportation Research Part D: Transport and Environment 58 (2018) 155-171. https://doi.org/10.1016/j.trd.2017.12.002.

19. J. Peng, D. Liu, J. Parnell, N. Kessissoglou: Influence of translational vehicle dynamics on heavy vehicle noise emission. Science of the Total Environment 689 (2019) 1358-1369. https://doi.org/10.1016/j.scitotenv.2019.06.426.

20. W.L. Luo, M. Cai, F. Li, J.K. Liu: Dynamic modeling of road traffic noise around building in an urban area. Noise Control Engineering Journal 60 (2012) 353-362.

21. A. Can, L. Leclercq, J. Lelong, D. Botteldooren: Traffic noise spectrum analysis: Dynamic modeling vs. experimental observations. Applied Acoustics 71 (2010) 764-770.

22. A. Can, E. Chevallier, M. Nadji, L. Leclercq: Dynamic traffic modeling for noise impact assessment of traffic strategies. Acta Acustica United with Acustica 96 (2010) 482-493.

23. F. Li, M. Cai, J.K. Liu, Z. Yu: Dynamic traffic noise simulation at a signalized intersection among buildings. Noise Control Engineering Journal 59 (2011) 202-210.

24. M. Cai, F. Li, J.K. Liu: Dynamic simulation and characteristics analysis of traffic noise at signal-controlled pedestrian crossing junction. Noise Control Engineering Journal 59 (2011) 549-555. 
25. C. Guarnaccia: Advanced tools for traffic noise modelling and prediction. Wseas Transactions on Systems 12 (2013) $121-130$.

26. W. Gardziejczyk, M. Motylewicz: Noise level in the vicinity of signalized roundabouts. Transportation Research Part DTransport and Environment 46 (2016) 128-144.

27. W.M. To, T.M. Chan: The noise emitted from vehicles at roundabouts. Journal of the Acoustical Society of America 107 (2000) 2760-2763.

28. D. Covaciu, D. Florea, J. Timar: Estimation of the noise level produced by road traffic in roundabouts. Applied Acoustics 98 (2015) 34-51.

29. R. Makarewicz, R. Golebiewski: Modeling of the roundabout noise impact. Journal of the Acoustical Society of America 122,2 (2007) 860-868.

30. E. Chevallier, L. Ledercq, J. Lelong, R. Chatagnon: Dynamic noise modeling at roundabouts. Applied Acoustics 70 (2009) $761-770$.

31. E. Chevallier, A. Can, M. Nadji, L. Leclercq: Improving noise assessment at intersections by modeling traffic dynamics. Transportation Research Part D Transport \& Environment 14 (2009) 100-110.

32. L. Estevez-Mauriz, J. Forssen: Dynamic traffic noise assessment tool: A comparative study between a roundabout and a signalised intersection. Applied Acoustics 130 (2018) $71-86$.

33. F. Li, Y.S. Lin, M. Cai, C.Y. Du: Dynamic simulation and characteristics analysis of traffic noise at roundabout and signalized intersections. Applied Acoustics 121 (2017) $14-24$.

34. K. Nagel, M. Schreckenberg: A cellular automaton model for freeway traffic. Journal De Physique I 2 (1992) 2221-2229.

35. Q.L. Li, B.H. Wang, M.R. Liu: An improved cellular automaton traffic model considering gap-dependent delay probability. Physica A-Statistical Mechanics and Its Applications 390 (2011) 1356-1362.
36. X. Ruan, J.Y. Zhou, H.Z. Tu, Z.R. Jin, X.F. Shi: An improved cellular automaton with axis information for microscopic traffic simulation. Transportation Research Part C-Emerging Technologies 78 (2017) 63-77.

37. C.Y. Wu, M. Li, R. Jiang, Q.Y. Hao, M.B. Hu: Perimeter control for urban traffic system based on macroscopic fundamental diagram. Physica A-Statistical Mechanics and Its Applications 5, 03 (2018) 231-242.

38. N. Lakouari, H. Ez-Zahraouy, A. Benyoussef: Traffic flow behavior at a single lane roundabout as compared to traffic circle. Physics Letters A 378 (2014) 3169-3176.

39. Y. Regragui, N. Moussa: A cellular automata model for urban traffic with multiple roundabouts. Chinese Journal of Physics 56 (2018) 1273-1285.

40. D.W. Huang: Modeling gridlock at roundabout. Computer Physics Communications 189 (2015) 72-76.

41. D.W. Huang: Phase diagram of a traffic roundabout. Physica A-Statistical Mechanics and Its Applications 383 (2007) 603-612.

42. N.P. Belz, L. Aultman-Hall, J. Montague: Influence of priority taking and abstaining at single-lane roundabouts using cellular automata. Transportation Research Part C 69 (2016) 134-149.

43. GB 1495-2002: Limits and measurement methods for noise emitted by accelerating motor vehicles. China Environmental Science Press, Beijing, 2002.

44. F. Li, S.S. Liao, M. Cai: A new probability statistical model for traffic noise prediction on free flow roads and control flow roads. Transportation Research Part D-Transport and Environment 49 (2016) 313-322.

45. GA 802-2019: Road traffic management-types of motor vehicles. Ministry of Public Security of the People's Republic of China, Beijing, 2019.

46. JTG B03-2006: Specifications for Environmental Impact Assessment of Highways. Ministry of Communications of the People's Republic of China, Beijing, 2006.

Cite this article as: Du C. Qiu X. Li F. \& Cai M. 2021. A simulation of traffic noise emissions at a roundabout based on a cellular automaton model. Acta Acustica, 5, 42. 